\title{
Strategies for Serving the Base of the Pyramid - Lessons from Sub-Saharan Africa
}

\author{
Dr. Adolf Johan Vögel \\ Department of Business Management, University of Pretoria \\ Email: johan.vogel@up.ac.za
}

\section{Doi:10.5901/mjss.2014.v5n23p702}

\begin{abstract}
Though the base of the pyramid has received an increasing amount of attention in the literature, few multinational enterprises have been able to build a sizeable business serving this market. In addition, most of what we do know seems to focus on India; little is known about sub-Saharan Africa. By analysing a case study of a firm that has achieved success in serving the base of the pyramid in sub-Saharan Africa, this paper identified that in the majority of cases the strategies identified are consistent with the current literature on the topic. The study did, however, identify partnering with national government and serve both the top as well as bottom of the pyramid in an attempt to maximise returns as two new strategies for serving the base of the pyramid.
\end{abstract}

Keywords: Base of the pyramid, Sub-Saharan Africa

\section{Introduction}

The saturation of developed markets is forcing multinational enterprises (MNEs) to look for new ways to grow their businesses, and in doing so they find themselves increasingly turning towards developing markets (Gollakota, Gupta, \& Bork, 2010; London \& Hart, 2004; Prahalad, 2004; Prahalad \& Hammond, 2002). But the opportunity for MNEs in developing markets is not just limited to serving the wealthy few, as there are huge opportunities in serving the lowincome segment of these markets (Anderson \& Billou, 2007; Prahalad, 2001). In fact it is estimated that four billion people in the world today live on less than US\$1500 - purchasing power parity (PPP) - per year (Anderson \& Billou, 2007; London \& Hart, 2004; Prahalad, 2001). Collectively this group, referred to by Prahalad (2001) as the base of the pyramid (BOP) has a purchasing power estimated at between US\$2 and US\$5 trillion per year (Karamchandani, Kubzansky, \& Lalwani, 2011; London \& Hart, 2004). In view of these statistics, it would seem to be good business strategy for a firm to be involved in such large, untapped markets that offer new customers, cost-saving opportunities, and access to radical innovation (Prahalad \& Hammond, 2002).

It would seem, however, that most MNEs that do expand into developing markets focus rather on the middle- and upper-income - "top of the pyramid (TOP)" (London \& Hart, 2004; Rivera-Santos \& Rufin, 2010) - segments of the market (Anderson \& Billou, 2007; London \& Hart, 2004), and that few MNE have been able to build a sizable business serving the BOP (Karamchandani et al., 2011; Olsen \& Boxenbaum, 2009). As the MNEs that do choose to focus on the BOP have had mixed success (Anderson \& Billou, 2007), there is a need to go beyond the rationale (why) and start to focus more on the mechanisms (how) for serving the BOP (Rashid \& Rahman, 2009).

In the existing literature there seems to be consensus among researchers (Gollakota et al., 2010; Hart, in Wheeler, McKague, Thomson, Davies, Medalye, \& Prada, 2005; London \& Hart, 2004; Prahalad \& Hammond, 2002; Rashid \& Rahman, 2009; Simanis, Hart, Enk, Duke, Gordon, \& Lippert, 2005) that we need to modify our view of strategy when focussing on the BOP. In fact, most firms that fail to thrive in the BOP have made the same fundamental error: they try to use the same business models, value systems, and supply chains that are more appropriate at the TOP (London \& Hart, 2004).

But while a great deal of BOP research has been focused on India (Anderson \& Billou, 2007; Gollakota et al., 2010; Prahalad, 2004; Prahalad \& Hammond, 2002), little is known about serving the BOP in sub-Saharan Africa (SSA). While India had a 2012 population of 1236700 000, of which an estimated 32.7 percent live on less than US\$1.25 per day (PPP) in 2010, SSA had a 2012 population of 910400 000, of which an estimated 48.5 percent live on less than US\$1.25 per day (PPP) in 2010 (World Bank, 2014(a)).

Though the BOP market in SSA is large, SSA consists of 47 countries (World Bank, 2014(b)), which will offer different challenges to an MNE considering serving this market, as each has its own political, economic and legal systems. Cultural practices can also vary dramatically, as can the education and skills level of the populations (Hill, 
2009). Adding to the complexity, SSA's population figures range from as much as 168800000 for Nigeria (2012 figures), of which 68 percent lived on less than US\$1.25 per day (PPP) in 2010 (World Bank, 2014(a)) to as little as 89170 for the Seychelles (2012 figures) (World Bank, 2014(c)), of which 0.3 percent live on less than US\$1.25 per day (PPP) in 2007 (World Bank, 2014(a)).

With Prahalad and Hammond (2002) suggesting that MNEs need to think creatively about their strategies if they want to succeed in BOP markets, and London and Hart (2004) and Rashid and Rahman (2009) warning that entering low-income markets in emerging economies may require a different strategic approach, this study identifies strategies an MNE needs to implement when serving the BOP in SSA.

\section{Literature Review and Propositions}

\subsection{Partner Selection}

Prahalad and Hammond (2002) warn against the misconceptions of serving the BOP, such as that: the poor have no money; the poor are too concerned with fulfilling their basic needs to waste their money on non-essential goods; and the BOP cannot use advanced technology. However, Karnani (2008) and Karamchandani et al. (2011) are of the opinion that we should not be unrealistic in our expectations of the consumers at the BOP. Due to their lack of education, lack of information, and economic, cultural and social deprivation, these are not rational consumers, and providing them with increased consumption choices will not necessarily increase their welfare.

In an attempt to better understand the BOP environment, Rivera-Santos and Rufin (2010) provide us with a much more detailed description of the environment facing an MNE. As can be seen from Figure 1, the characteristics of the BOP competitive and institutional environments are very different from those at the TOP; this has important implications for new entrants and, more generally, for the way in which business is conducted at the BOP (Rivera-Santos \& Rufin, 2010). Moreover, London and Hart (2004) have identified the lack of environmental knowledge of BOP markets as one of the major reasons for the failure of MNEs to successfully serve this market.

Figure 1: The BOP environment

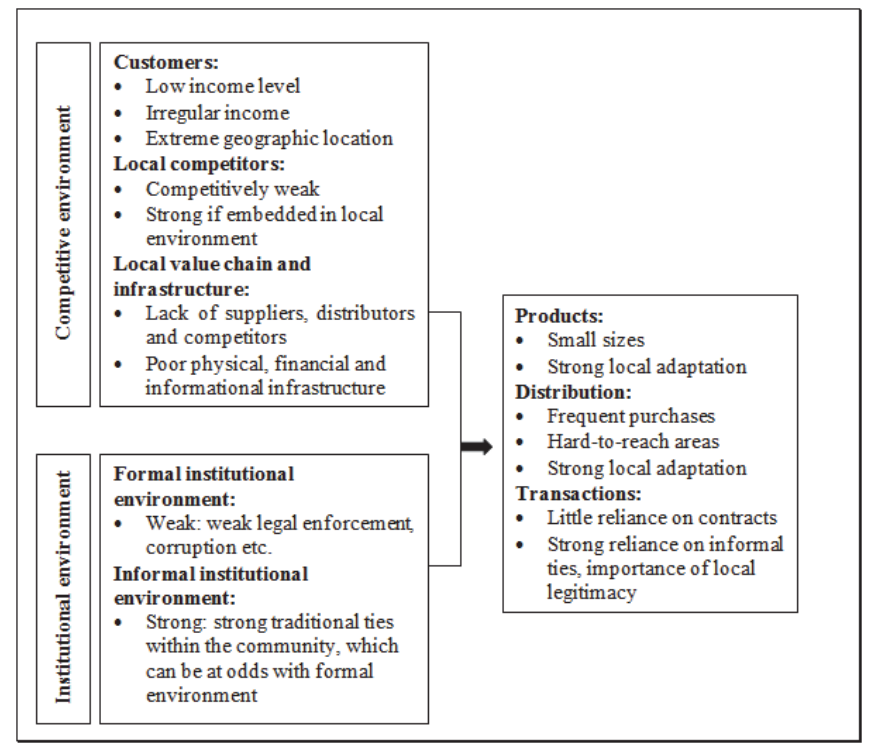

Source: Rivera-Santos and Rufin (2010)

Considering that it takes around four and a half years for a firm to learn what it does not know about a new foreign market at the time of entry (Parker, 2009; Petersen, Pedersen, \& Lyles, 2008), an effective local partner in a BOP market can not only radically shorten and improve the settling-in period (Parker, 2009; Rashid \& Rahman, 2009) but also limits the risk while maximising existing infrastructure, both physically and socially (Prahalad \& Hammond, 2002). A local partner can also aid a subsidiary by (Gollakota et al., 2010; London \& Hart, 2004; Parker, 2009; Simanis et al., 2005): 
- helping to detect new market opportunities;

- adapting production processes and product features;

- establishing marketing channels;

- implementing technical support;

- analysing customer feedback; and

- absorbing and integrating ideas and knowledge from both inside and outside the firm.

According to London and Hart (2004), Rivera-Santos and Rufin (2010) and Prahalad and Hammond (2002), successful BOP strategies rely heavily on non-traditional partners. These partners include non-profit organisational and community groups, as well as local and even village-level government, as these partners are considered to be able to provide information on the local context, local legitimacy, and access to needed resources. London and Hart (2004) believe that unsuccessful strategies, on the other hand, primarily rely on traditional partners such as national government and large local firms. These more traditional partners may be as far removed, in terms of business knowledge of lowincome markets, as the firms trying to launch the venture.

In contrast, Leisinger (2007) is of the opinion that cooperation with governments and multilateral institutions has been more straight-forward than cooperation with NGOs. While Parker (2009) states that the lack of resources and underdeveloped nature of the infrastructure in most SSA countries may be extremely challenging, the converse also holds true, in that they create opportunities for the local MNE subsidiary to partner with government in arriving at a win/win solution to mutual problems. According to the Coca Cola Company, the continuous and active engagement of governments in SSA is a key activity for the company, as it is not considered good practice to go to government only when you have a problem (Parker, 2009).

On the basis of the literature, there seems to be consensus concerning the need to find a local partner, and in particular a non-traditional partner such as an NGO or community group. However, the lack of consensus as to the value of partnering with national government has led to the following proposition:

Proposition 1: When entering BOP markets in SSA, MNEs should partner with national government.

\subsection{Cost Cutting and Product Adaptation}

According to Gollakota et al. (2010), Hart (in Wheeler et al., 2005), and Simanis et al. (2005), MNEs need to modify their view of strategy when focussing on the BOP. According to these authors, consumers at the BOP have significantly lower purchasing power than the consumers MNEs normally strategise for. As a result, an MNE needs to reduce its costs if it wants to reach consumers at the BOP. As customers at the BOP have a low disposable income and receive their income on a daily rather than weekly or monthly basis, products should not only be affordable but should also match customers' cash-flow (Anderson \& Billou, 2007).

Though lowering costs through using cheaper inputs or dropping packaging sizes has sometimes allowed firms to reach BOP consumers, not even global cost leaders always have sufficient low-cost structures to be able to serve the BOP if they do not make some fundamental changes (Gollakota et al., 2010; Karamchandani et al., 2011; London \& Hart, 2004). According to Gollakota et al. (2010), deep cost management is based on two elements: identifying core value that must be offered and stripping out other elements that add costs; and re-engineering the operations of the firm using a holistic approach. According to Christensen and Raynor (in Gollakota et al., 2010), the concept of core value, devoid of all frills, requires an understanding of the essential needs that the product/service satisfies, taking into account the circumstances of the consumer. London and Hart (2004) support Gollakota et al. (2010) when stating that a firm will be able to generate significant revenue by creating a low-cost manufacturing and distribution process that does not rely on the legal protection of intellectual property. As there are in most cases few firms in any particular industry who have successfully developed propositions for very low-income consumers, MNEs might need to look towards firms with other products and services for inspiration on how to accomplish this (Anderson \& Billou, 2007).

London and Hart (2004), however, warn against merely removing some of the existing functionality in an attempt to create a low-cost version of a mainstream product. Low-income markets are better served if the firm co-designs a product from the bottom up (as opposed to the top down) with local partners who understand what functionalities are most important to BOP customers. Anderson and Billou (2007) support this view, stating that in order for an MNE to have its products and services accepted in BOP markets, it needs to ensure that its products and services are adapted to the unique needs of both the customers and the distributors.

In one particular instance, an MNE decided to forgo adopting the traditional pricing model of cost plus margin, by first identifying the appropriate selling price and then designing a product and business model that provided the 
functionality required and offered profit margins that were acceptable for a high-volume business (London \& Hart, 2004).

Based on the need for both cost cutting and product adaptation, this paper has stated the following two propositions:

Proposition 2a: In serving BOP markets in SSA, an MNE needs to reduce the cost of its product or service by identifying the core value that must be offered and stripping out all other elements that add costs.

Proposition 2b: When serving BOP markets in SSA, an MNE needs to ensure that its product or service is adapted to the unique needs of the customers.

\subsection{Distribution}

Distribution channels in the developing world - unlike those in the developed world - can be fragmented or non-existing; the task of getting the product to the market can be difficult to accomplish and add costs (Anderson \& Billou, 2007). Although customers are numerous, they are often rural and scattered, and it is difficult for firms to manage the face-toface (and cash-based) interaction that is typically necessary for building a cost-effective distribution business. Channels built for middle-class and high-income customers do not reach the poor, and extending them can be prohibitively expensive (Karamchandani et al., 2011; London \& Hart, 2004). Solving this problem may mean building a dedicated channel to serve the market.

Innovative firms have found ways to reach low-income consumers through alternative channels that can provide additional value to customers, or have teamed up with partners that have extensive reach in the market (Karamchandani et al., 2011). London and Hart (2004) suggest encouraging entrepreneurship by local distributors by providing flexibility in how the final product or service could be marketed or delivered. As existing distribution channels designed for middle and high-income customers do not adequately serve the BOP market, the following proposition was stated:

Proposition 3: An MNE needs to develop a new distribution channel focusing specifically on the BOP market.

\subsection{Benefit to Society}

London and Hart (2004), and Parker (2009) suggest that firms interested in targeting BOP markets should consider both societal performance and the sharing of resources outside firm boundaries - local capacity building - in order to be successful. Successful ventures address societal performance by incorporating local capacity-building directly into their business model rather than through the more conventional approach of corporate philanthropy as an activity separate from the business (London \& Hart, 2004). London and Hart (2004) call this global capability "social embeddedness" or the ability to create competitive advantage based on a deep understanding of and integration with the local environment.

Parker (2009) adds that by listing on the local stock exchange - if one exists - firms can reserve a meaningful share of the subsidiary for local participation. Subsidiaries should also encourage outsourcing to local entrepreneurs including large portions of the distribution chain - while establishing the necessary control environment and effective training and support systems. As a result, the subsidiary will not only be viewed in a positive light, but also gain valuable local knowledge and influence. The social impact of a firm on the BOP can be summed up by Olsen and Boxenbaum's (2009) definition of serving the BOP, as "the creation of new profit-seeking market opportunities to low-income segments in the developing world with the simultaneous goal of contributing to the resolution of significant societal problems in these regions". As a result the following proposition was stated:

Proposition 4: When serving the BOP in SSA, an MNE should ensure that it contributes to the resolution of a societal problem in the country.

\subsection{Market Size}

"A fundamental obstacle that stands in the way of any business wishing to invest profitably in an SSA country is that of constrained size" (Parker, 2009). As was indicated in the introduction, a country such as the Seychelles has a population of 89170 (World Bank, 2014(c)) of which 0.3 percent lived on less than US\$1.25 per day (PPP) (World Bank, 2014(a)). As a result, MNEs and their subsidiaries operating in SSA need to extract maximum returns from each of their operations without exploiting the consumers or host country in the process. This includes exploring opportunities at both the BOP and TOP. Once an MNE has expanded into a market, the MNE possesses in-country growth opportunities, providing a platform for expanding into other products in the host country or, in line with the concept of world-wide learning, into neighbouring markets (London \& Hart, 2004; Parker, 2009; Tong, Alessandri, Reuer, \& Chintakananda, 2008). Due to the possible constrained market size in SSA, the following proposition was stated: 
Proposition 5: Due to the possible constrained market size in SSA markets, an MNE wishing to serve the BOP needs to exploit possibilities at the top as well as the bottom of the economic pyramid.

\section{Research Methodology}

This qualitative study follows a dual approach. Firstly, the paper explores the existing BOP literature in an attempt to determine the existing strategic approaches to serving the BOP. Secondly, in determining how best to serve the BOP in SSA, the paper combines these findings with the analysis of a case study of a firm - Kenya Breweries Ltd (KBL) considered to have achieved success in serving the BOP.

In selecting the most appropriate research strategy, consideration was given to Yin's (2003) view that the most important condition for differentiating among the various research strategies is to identify the type of research question being asked. "How" and "why" questions are likely to favour the use of case studies, experiments, or histories. As this paper aimed to determine how firms serve the BOP in SSA, a descriptive case study was chosen. The holistic, singlecase design was chosen because the case complies with Yin's (2003) rationale for using a single case, namely that the particular case represents a unique case. The use of a single case is supported by Flyvbjerg (2006) when stating that a critical case should be used if it has strategic importance in relation to the general problem. With a large percentage of BOP cases focusing on India (Anderson \& Billou, 2007; Gollakota et al., 2010; Prahalad, 2004; Prahalad \& Hammond, 2002), the KBL case gives us a unique perspective on strategies to pursue when serving the BOP in SSA. Secondly the case study design was holistic, as the case study examined only the global nature of the organisation and no attempt was made to use the case study for more than one unit of analysis (Yin, 2003). A single case design seems to be a popular design to use when studying firms' approaches to serving the BOP; this design was also used by Olsen and Boxenbaum (2009) and Rashid and Rahman (2009) in their analysis of the BOP.

\section{Senator Keg Lager - Case Study}

In November 2000, at least 140 Kenyans died, many went blind and hundreds of others were hospitalised after consuming illegally brewed and poisonous liquor called kumi kumi in the poor neighbourhoods of Mukuru Kwa Njenga and Mukuru Kaiyaba (Oladipo, 2008; World Health Organisation, 2004). In June 2005, 51 people died and dozens were blinded after drinking a particularly toxic batch of home brew laced with battery acid in a district outside Nairobi (Barclay, 2008). In many of Kenya's low-income urban and rural areas, people who find conventional legal beer too expensive often resort to cheap home brews. Made from sorghum, maize or millet, the alcoholic drink often contains dangerous substances that the producers believe will speed up fermentation; they use harmful additives such as fertilisers, battery acid, or formalin (Barclay, 2008; Oladipo, 2008; World Health Organisation, 2004).

In a country where half of the 32 million population live on less than US\$1 a day, mainstream beer such as East African Breweries Ltd's (EABL) Tusker Lager, which sells for US $\$ 0.75$ to US $\$ 3$ a bottle, is out of reach for most Kenyans (Barclay, 2008; Parker, 2009). As a result the informal brews account for roughly 50 percent of all alcoholic beverages consumed in Kenya (Barclay, 2008; Parker, 2009).

$\mathrm{KBL}$, however, saw an opportunity to produce a cheap beer that was also safe (Oladipo, 2008; Parker, 2009) and in November 2004 KBL, with the support of the Kenyan government, launched Senator Keg, a barley beer in a keg format providing an affordable, high quality and hygienic alternative to illicit brews (EABL, 2010; Oladipo, 2008). KBL is owned by two MNEs, SABMiller, which owns 20 percent, and Diageo, owning the other 80 percent through its majority ownership in EABL (Parker, 2009).

The challenge facing KBL was how to produce and sell a beer that would be able to compete with these illegal brews containing between 40 and 50 percent alcohol and selling for around 13 US cents per glass (Barclay, 2008; Bowers, 2007).

To overcome the problem KBL had to be innovative. It had to produce a beer containing six percent alcohol (Bowers, 2007; Oladipo, 2008; Parker, 2009) (which would entice the low-income Kenyans to rather consume the legal beer) while still being able to produce a beer that would be affordable. In so doing it needed to convince the Kenyan government to reduce the excise tax on Senator Keg in an attempt to bridge the affordability gap (Barclay, 2008; Bowers, 2007; Parker, 2009). By offering Senator Keg in a keg, KBL was able to eliminate packaging costs; however, this meant it had to invest heavily in draught dispensing equipment (Bowers, 2007; EABL, 2010; Parker, 2009). KBL also made use of locally grown barley, further reducing its costs (Bowers, 2007). However, by agreeing with the Kenyan government to make Senator Keg available exclusively in those areas where illicit brews had become a problem, KBL had to employ a separate sales and distribution organisation (Parker, 2009). 
The cost savings meant that Senator Keg could be sold for Ksh 20 for 300ml, Ksh 30 for $500 \mathrm{ml}$ and Ksh 66 for a one-litre unit. This means that Senator Keg sells for half the price of EABL's Tusker Lager with its retail price of Ksh 60 for a 500ml bottle (EABL, 2010; Parker, 2009).

The introduction of Senator Keg into the Kenyan market has proved to be a success, with Senator Keg sales reaching one million hectolitres in just 18 months (Parker, 2009), accounting for five percent of beer consumed in Kenya (Bowers, 2007). In more general terms, in Nairobi alone distributors deliver 8000 x 50 litre Senator Kegs a day (Barclay, 2008), forcing KBL to expand its production capacity dedicated to producing the product (Parker, 2009). As a result of the reduction of illicit brews, the government has decided to eliminate all excise tax on Senator Keg (Bowers, 2007; Parker, 2009).

Since its early signs of success in Kenya, EABL has begun discussions with other governments struggling with problems of illicit alcohol. Inquiries have come from South Africa and a number of West African countries (Bowers, 2007). And another EABL subsidiary - Uganda Breweries Ltd (UBL) - is already following in its Kenyan counterpart's footsteps, with the Ugandan government agreeing to reduce excise tax from 30 to 20 percent on beer made from local materials, thus enabling UBL to reduce the price of Senator Keg in Uganda as well (Ssali, 2008).

\section{Discussion}

\subsection{Partner Selection}

As both the competitive and institutional environments of the BOP vary greatly from those of the TOP (Rivera-Santos \& Rufin, 2010), a number of authors have suggested that finding a local partner will not only shorten the settling in period but also reduce the risk of doing business at the BOP (Gollakota et al., 2010; London \& Hart, 2004; Parker, 2009; Prahalad \& Hammond, 2002; Rashid \& Rahman, 2009; Simanis et al., 2005). London and Hart (2004) are, however, of the opinion that unsuccessful strategies, primarily rely on traditional partners such as national government and large local firms. According to the authors, traditional partners are as far removed in terms of business knowledge of low-income markets as the firms trying to launch the venture.

When considering this statement by London and Hart (2004) it is interesting to note that Vodacom, South Africa's largest cell phone company, developed an interest in serving the BOP as a result of a condition mandated by the South African government. Vodacom had to offer 22000 cellular lines in under-served areas in order to receive one of two GSM network licences (Gollakota et al., 2010). This indicates that the South African government is not as far removed from the BOP market as the governments in London and Hart's (2004) study.

In the case of Senator Keg, KBL had the challenge of reducing its costs in order to compete with the illicit brews selling for around 13 US cents per glass. In meeting the challenge, KBL was able to reduce its costs by negotiating with the Kenyan government to reduce the excise tax on Senator Keg. Due to the success of Senator Keg, the Kenyan government later eliminated the excise tax on this product completely. In Uganda, the Ugandan government has agreed to cut the excise tax on beer produced from locally produced ingredients from 30 percent to 20 percent (Ssali, 2008), in doing so helping UBL to reduce the cost of producing Senator Keg so as to serve the BOP in Uganda.

As KBL's partnership with the Kenyan government helped it to reduce the cost of manufacturing Senator Keg, and in doing so reduced its costs sufficiently to focus on the BOP, there is enough support for the proposition that when entering BOP markets in SSA, MNEs should partner with national government.

\subsection{Cost Cutting and Product Adaptation}

The BOP literature indicates that two forces dominate MNEs' attempts to expand into and conduct business in BOP markets: the need to cut costs and the need to adapt products and services to local tastes, needs and conditions (Anderson \& Billou, 2007; Gollakota et al., 2010; London \& Hart, 2004; Prahalad, 2001; Prahalad \& Hammond, 2002). $\mathrm{KBL}$ was faced with exactly these forces, as it not only needed to reduce its costs in order to compete with illegal brews selling for 13 US cents per glass, but also had to create a product that would be able to compete with illicit brews containing between 40 and 50 percent alcohol. In cutting its costs, KBL had to do more than negotiate with the Kenyan government to reduce the excise tax on Senator Keg. KBL had to create a product manufactured from locally grown barley and offered in a keg, so as to eliminate packaging costs. This, however, meant that it had to invest heavily in draught-dispensing equipment. By doing so it was able to create a beer containing six percent alcohol that sold for half the price of main stream beers, at a mere Ksh 20 for $300 \mathrm{ml}$, Ksh 30 for $500 \mathrm{ml}$ and Ksh 66 for a one-litre unit.

By developing a new product focused on the needs of the low-income market and not merely introducing products 
from Western markets with some minor adaptations, KBL was not asking distributors to cannibalise their existing product offering. The new product rather encouraged consumers of illegal brews to enter the main-stream market and in so doing opened up new low-income markets to distributors.

Therefore the findings from the case support both the proposition stating that in serving BOP markets an MNE needs to reduce the cost of its product or service by identifying the core value that must be offered and stripping out all other elements that add costs and the proposition stating that when serving BOP markets in SSA an MNE needs to ensure that its product or service is adapted to the unique needs of the customers.

\subsection{Distribution}

Meeting the above-mentioned affordability and acceptability requirements (Anderson \& Billou, 2007) was, however, not without its challenges. Not only did KBL have to invest heavily in draft dispensing equipment, but distributing the kegs to those areas where illicit brews were normally consumed meant that KBL had to employ a separate sales and distribution organisation. However, by doing this not only was KBL able to overcome the distribution challenge identified by Prahalad and Hammond (2002), Anderson and Billou (2007), and Gollakota et al. (2010), but its separate sales organisation was also able to help it overcome Anderson and Billou's (2007) awareness challenge. In addition, as indicated above, distributors did not have to cannibalise their existing product offering, as the new product encouraged consumers of illegal brews to enter the main-stream market and thus opened up new low-income markets to distributors. The case of Senator Keg thus provides enough support for the proposition stating that an MNE needs to develop a new distribution channel focusing specifically on the BOP market in SSA.

\subsection{Benefit to Society}

According to London and Hart (2002), and Olsen and Boxenbaum (2009), there is increasing pressure on MNEs to take a greater role in addressing global societal issues such as eradicating poverty and environmental protection in developing countries. In the case of KBL, it was not only able to open up new growth opportunities by producing Senator Keg (in just 18 months, Senator Keg accounted for five percent of beer consumed in Kenya) but in the process KBL was able to help the Kenyan government with a major social issue, the reduction in the sale of illicit alcohol. The launch of Senator Keg was so successful in achieving this that the Kenyan government has decided to eliminate all excise tax on the sale of Senator Keg. The initial success of Senator Keg in Kenya has also meant that EABL has begun discussions with other SSA governments struggling with problems of illicit alcohol, while another EABL subsidiary - UBL - is already following in its Kenyan counterpart's footsteps with the launch of Senator Keg in Uganda.

Secondly, by using only locally grown barley, KBL supports local suppliers while managing to reduce the cost of producing Senator Keg. Using local suppliers is an initiative popular with MNEs in SSA. For instance, SABMiller partnering with FARM-Africa - is working with 2000 local small-scale farmers in South Sudan to grow cassava which SABMiller will buy to use in beer production. It is expected that this initiative will bring direct and significant long-term market opportunities to these 2000 small-scale farmers, with dependants and other employment effects ensuring that approximately 15600 people could benefit in three years (SABMiller, n.d.; Seko, 2011).

Based on these findings there is sufficient support for the proposition: When serving the BOP in SSA, an MNE should ensure that it contributes to the resolution of a societal problem in the country.

\subsection{Market Size}

A great deal of BOP research and cases focus on large markets such as India (Anderson \& Billou, 2007; Gollakota et al., 2010; Prahalad, 2004; Prahalad \& Hammond, 2002). However, MNEs might find that a major obstacle facing them in SSA is that of constrained market size (Parker, 2009). As was indicated in the introduction, the 47 countries making up SSA (World Bank, 2014(b)) all vary in population size from as much as 168800000 for Nigeria to as little as 89170 for the Seychelles (World Bank, 2014(a); World Bank, 2014(c)). According to Parker (2009), MNEs and their affiliates operating in poor countries need to "extract maximum returns from each of their positions". He uses the example of MTN who has managed to extend its user base through SSA by offering a range of call options that range from pre-paid cards and short message service (SMS) facilities for poor consumers to monthly account and internet facilities aimed at the topend market.

In the case of KBL, KBL is selling a brand such as Tusker Lager to the top end of the market while Senator Keg is aimed at the BOP. According to Tong et al. (2008) and Parker (2009), once the MNE has successfully expanded into 
such a low-income market, the MNE will possess in-country growth opportunities, providing a platform for expanding into other products in the host country or in neighbouring markets. With Senator Keg this was the case, as EABL was able to use the experience gained through $\mathrm{KBL}$ to launch Senator Keg in Uganda. Meanwhile in Uganda, UBL is selling Windhoek Lager at the top end of the market and Senator Keg at the BOP. In doing so both KBL and UBL are exploring opportunities at both the BOP and the TOP so as to extract maximum returns in markets much smaller than India.

In looking at the findings of the case, there seems to be sufficient support for the proposition that due to the possible constrained market size in SSA markets, an MNE wishing to serve the BOP market needs to exploit possibilities at the top as well as the bottom of the economic pyramid.

\section{Conclusion}

With most of the existing BOP research focused on large markets such as India, this paper aimed to determine which strategies MNEs needed to implement in order to serve the BOP in SSA. Based on the findings of the Senator Keg case, it can be stated that in the majority of cases the strategies identified are consistent with the current literature on the topic. In particular, the study found that when serving the BOP market in SSA, an MNE needs to reduce the cost of its product or service by identifying the core value that must be offered to customers and stripping out all other elements that add costs. At the same time the MNE should ensure that its product or service is adapted to the unique needs of the customer and not just merely adaptations of products or services already being sold in TOP markets.

By designing unique products focused on the BOP, MNEs are not only meeting the needs of the BOP customers; they are also avoiding the cannibalisation of distributors' existing markets by, as in the case study, encouraging BOP consumers to enter the main-stream market and in doing so opening new low-income markets for distributors.

By supporting the need for both cost cutting and product adaptation in serving BOP markets, this research acknowledges the transnational strategy as the dominant strategy for achieving success at the BOP in SSA. However, the research also supports London and Hart's (2004) call for the inclusion of social embeddedness as an additional capability for serving the BOP, over and above the capabilities synonymous with the transnational strategy - global efficiency, national responsiveness and world-wide learning. In the case, KBL was able to capture five percent of the beer market in Kenya within 18 months, as it was focused on providing an affordable, high-quality and hygienic alternative to illicit brews in a country where 50 percent of all alcohol sold was illicit brews.

The findings of this paper further support the need for the development of a new distribution channel focusing on the BOP market, as the existing channels focusing on TOP consumers are not able to reach the BOP.

The study did, however, identify two new strategies for serving the BOP. First the research highlighted the value of partnering with national government in a region where continuous and active engagement with national governments is considered crucial. Partnering with national government can help to reduce costs, as was the case with $\mathrm{KBL}$, where the government agreed to reduce the excise tax on Senator Keg so as to make the product more affordable in an attempt to reduce the consumption of illicit brews.

Secondly, as BOP markets in SSA are not as big as in a country like India, MNEs should serve both the TOP and BOP markets in an attempt to maximise their returns. Once an MNE has gained sufficient knowledge and economies of scale in serving the BOP in one country, it can use this knowledge to expand into other BOP markets, as was the case with EABL with the launch of Senator Keg in Uganda.

\section{Limitations and Future Research}

Though the paper has briefly referred to cases in other countries and in other industries, the paper primarily focused on one industry in one SSA country. By analysing cases in other industries and in other SSA countries, the stated propositions could be tested further.

\section{References}

Anderson, J., \& Billou, N. (2007). Serving the world's poor: Innovation at the base of the economic pyramid. Journal of Business Strategy, 28(2), 14-21.

Barclay, E. (2008). In Kenya, Obama (Beer) wins big. [Online] Available: http://www.businessweek.com/print/bwdaily/ dnflash/content/mar2008/db20080326_3 (February 12, 2010).

Bowers, S. (2007). Diageo: Solve Kenya's drink problem with cheap beer. [Online] Available: http://www.guardian.co.uk/business/ 2007/dec/11/kenya.internationalnews/print (February 12, 2010) 
EABL (East African Breweries Limited). (2010). Senator. [Online] Available: http://www.eabl.com/brandsinner.asp?cat= senator\&subcat=brands (February 12, 2010)

Flyvbjerg, B. 2006. Five misunderstandings about case-study research. Qualitative inquiry, 12, 219-245.

Gollakota, K., Gupta, V., \& Bork, J. T. (2010). Reaching customers at the base of the pyramid - A two-stage business strategy. Thunderbird International Business Review, 52(5), 355-367.

Hill, C. W. L. (2009). International business: Competing in the global marketplace. (7th ed.). New York: McGraw-Hill.

Karamchandani, A., Kubzansky, M., \& Lalwani, N. (2011). Is the bottom of the pyramid really for you? Harvard Business Review, 89(3), 107-111.

Karnani, A. (2008). Help, don't romanticize the poor. Business Strategy Review, 19(2), 48-53.

Leisinger, K. M. (2007). Corporate philanthropy: The "Top of the Pyramid". Business and Society Review, 112(3), 315-342.

London, T., \& Hart, S. L. (2004). Reinventing strategies for emerging markets: Beyond the transnational model. Journal of International Business Studies, 35(5), 350-370.

Oladipo, T. (2008). Kenyan beer stirs Obamamania. [Online] Available: http://newsvote.bbc.co.uk/mpapps/pagetools/print/news. bbc.co.uk/2/hi/africa/7251273 (February 12, 2010)

Olsen, M., \& Boxenbaum, E. (2009). Bottom-of-the-pyramid: Organizational barriers to implementation. California Management Review, 51(4), 100-125.

Parker, A. C. (2009). A qualitative study of key success factors for multinational corporations operating in sub-Sahara Africa. [Online] Available: http://scholar.sun.ac.za/handle/10019.1/1929 (February 12, 2010)

Petersen, B., Pedersen, T., \& Lyles, M. A. (2008). Closing knowledge gaps in foreign markets. Journal of International Business Studies, 39(7), 1097-1113.

Prahalad, C. K. (2001). The bottom of the pyramid. Siliconindia, 5(10), 76-77.

Prahalad, C. K. (2004). Why selling to the poor makes for good business. Fortune, 150(10), 70-72.

Prahalad, C. K., \& Hammond, A. (2002). Serving the world's poor, profitably. Harvard Business Review, 80(9), 48-57.

Rashid, A. T., \& Rahman, M. (2009). Making profit to solve development problems: The case of Telenor AS and the Village Phone Programme in Bangladesh. Journal of Marketing Management, 25(9/10), 1049-1060.

Rivera-Santos, M., \& Rufin, C. (2010). Global village vs. small town: Understanding networks at the base of the pyramid. International Business Review, 19(2), 126-139.

SABMiller. (n.d.). Farming better futures. [Online] Available: http://www.sabmiller.com/files/pdf/SABMiller_Farming_Better_Futures.pdf (January 4, 2012)

Seko, L. (2011). Building a country one brick and dollar at a time. Forbes Africa, December 2011 - January 2012, 36-38.

Simanis, E., Hart, S., Enk, G., Duke, D., Gordon, M., \& Lippert, A. (2005). Strategic initiatives at the base of the pyramid: A protocol for mutual value creation. [Online] Available: http://www.bop-protocol.org (December 21, 2010)

Ssali, M. J. (2008). Uganda: Kalagala islanders say Bidco must stop destroying forests. [Online] Available: http://allafrica.com Istories/printable/200806180505.html (February 12, 2010)

Tong, T. W., Alessandri, T. M., Reuer, J. J., \& Chintakananda, A. (2008). How much does country matter? An analysis of firms' growth options. Journal of International Business Studies, 39(3), 387-405.

Wheeler, D., McKague, K., Thomson, J., Davies, R., Medalye, J., \& Prada, M. (2005). Creating sustainable local enterprise networks. MIT Sloan Management Review, 47(1), 32-40.

World Bank. (2014(a)). Poverty and equity data. [Online] Available: http://povertydata.worldbank.org/poverty/home (March 26, 2014)

World Bank. (2014(b)). Sub-Saharan Africa. [Online] Available: http://data.worldbank.org/region/sub-saharan-africa (March 26, 2014)

World Bank. (2014(c)). Seychelles. [Online] Available:http://www.worldbank.org/en/country/seychelles (October 27, 2014)

World Health Organisation. (2004). Global status report on alcohol 2004. [Online] Available: http://www.who.int/substance_ abuse/publications/en/kenya.pdf (February 12, 2010)

Yin, R. K. (2003). Case study research: Design and methods. (3rd ed.). Thousand Oaks, CA: Sage Publications. 